\title{
FAKTOR RISIKO KELUHAN COMPUTER VISION SYNDROME (CVS) PADA OPERATOR WARUNG INTERNET DI KECAMATAN BOJONG GEDE, KABUPATEN BOGOR TAHUN 2017
}

\author{
Andi Asnifatima ${ }^{1)}$, Imam Prakoso ${ }^{2)}$ dan Anissatul Fatimah ${ }^{3)}$ \\ ${ }^{1)}$ Program Studi Kesehatan Masyarakat, Fakultas Ilmu Kesehatan Universitas Ibn Khaldun Bogor \\ email: andiasnifatimah@gmail.com
}

\author{
${ }^{2)}$ Konsentrasi Kesehatan dan Keselamatan Kerja, Program Studi Kesehatan Masyarakat, Fakultas Ilmu Kesehatan Universitas Ibn \\ Khaldun Bogor \\ email: Imamprakoso137@gmail.com
}

${ }^{3)}$ Program Studi Kesehatan Masyarakat, Fakultas Ilmu Kesehatan Universitas Ibn Khaldun Bogor email: anissatul_fathimah@yahoo.com ${ }^{3)}$

\begin{abstract}
ABSTRAK
Peningkatan penggunaan komputer membawa sejumlah masalah kesehatan pada mata yang disebut Computer Vision Syndrome (CVS) yang menggambarkan masalah penglihatan yang terkait dengan lamanya pengunaan komputer. Di Indonesia sekitar 2,1 juta orang menggunakan komputer dan mengakses internet melalui Warung Internet (Warnet) sebesar 187,93 jam per bulan. Penelitian ini bertujuan untuk menganalisis hubungan faktor-faktor risiko dengan keluhan Computer Vision syndrome (CVS) pada Operator Warung Internet di Kecamatan Bojong Gede, Kabupaten Bogor tahun 2017. Penelitian ini bersifat kuantitatif dengan metode cross sectional menggunakan sampel jenuh sebanyak 50 orang pekerja operator warung internet. Data dianalisis dengan uji statistic chi square dan analisis regresi logistik. Hasil menunjukan $76 \%$ operator warnet mengalami CVS, gejala utama mata lelah dan tegang $(80 \%)$ dengan faktor risiko usia $<40$ tahun $(92 \%)$, waktu istirahat $<2$ jam $(56 \%)$, durasi penggunaan computer $>4$ jam $(82 \%)$, sudut penglihatan lebih tinggi $(60 \%)$, jarak penglihatan $<50 \mathrm{~cm}(66 \%)$. Kesimpulannya terdapat hubungan yang bermakna antara waktu istirahat ( $p$-value 0,016$)$, durasi penggunaan komputer $(p$-value 0,027$)$, sudut penglihatan ( $p$-value 0,035), dan jarak penglihatan ( $p$-value 0,047$)$ dengan CVS dan yang paling berisiko durasi penggunaan computer (OR 27 kali). Disarankan mengurangi menatap monitor dan memasang software pengingat waktu istirahat.
\end{abstract}

Kata Kunci : Computer Vision Syndrome (CVS), Warung Internet (Warnet), Faktor Risiko

\section{Pendahuluan}

Sebagai teknologi yang terus berkembang, komputer telah menjadi bagian dari kehidupan sehari-hari (Shelly et al., 2011). Akan tetapi Peningkatan penggunaan komputer ditempat kerja telah membawa perkembangan sejumlah masalah kesehatan termasuk masalah kesehatan pada mata.

Masalah kesehatan mata yang berkaitan dengan penggunaan komputer ini disebut Computer Vision Syndrome (CVS). Menurut American Optometric Association (AOA) mendefinisikan CVS sebagai gejala visual yang diakibatkan dari interaksi dengan display komputer atau lingkungan hidupnya.. CVS menggambarkan masalah penglihatan yang terkait dengan lamanya pengunaan komputer, tablet, e-reader dan ponsel.

Banyak orang mengalami ketidaknyamanan pada mata dan masalah penglihatan saat melihat layar digital untuk waktu yang lama. Tingkat ketidaknyamanan ini tampaknya meningkat dengan jumlah penggunaan layar digital (Supriyanto, 2014). Hal tersebut dapat 
meningkatkan insidensi CVS terutama jika faktor-faktor risiko yang ada tidak dideteksi dan dicegah lebih awal.

Data survei dari Asosiasi Penyelenggara Jasa Internet Indonesia (APJII) tahun 2016 mengungkap bahwa rata-rata pengakses internet di Indonesia yang menggunakan komputer yaitu 2,2 juta orang atau 1,7 persen. Pekerja atau wiraswasta yang memiliki nilai penggunaan komputer sebesar 82,2 juta orang atau $62 \%$ di Indonesia. Berdasarkan tempat paling sering mengakses internet dengan computer adalah Warung Internet (Warnet), ditemukan sekitar 2,1 juta orang atau 1,6\% dan penggunaan PC komputer sebesar $11,6 \%$.

Berdasarkan Badan Pusat Statistik (BPS) tahun 2011, pelanggan di warung internet memiliki akses lama internet sebesar 187,93 jam per bulan. Dari total resonden pengguna internet di Indonesia sebesar 132,7 juta orang. Sekitar 86,3 juta orang atau $65 \%$ dari angka total pengguna internet di Indonesia berada di Pulau Jawa yang merupakan angkata tertinggi (APJII, 2016). Jumlah warung internet di provinsi Jawa Barat sebesar 2,8 ribu unit tertinggi kedua dari jawa timur sebesar 3,6 ribu unit (BPS, 2014)

Menurut Shantakumari (2014), keluhan CVS yang paling umum dilaporkan di kalangan pengguna komputer pada mahasiswa di Ajman, Uni Emirate adalah sakit kepala 53,3\%, sensasi terbakar di mata 54,8\% dan mata lelah $48 \%$. Penelitian di Malaysia Sebanyak $42,9 \%$ berisiko munculnya kehulahan CVS disebabkan karena penggunaan komputer secara terus menerus lebih dari 2 jam tanpa mengambil setiap istirahat serta 20\% menggunakan komputer selama 4 sampai 6 jam per hari (Sen et al., 2007).

Berdasarkan hasil studi pendahuluan yang dilakukan pada operator warung internet di daerah Kecahatan Bojong Gede Kebapaten Bogor, ditemukan sebanyak 50 warung internet mempunyai jam kerja operasional selama 15 jam dari jam 7 pagi sampai dengan 10 malam. Sementara itu, jam kerja operator komputer warung internet yang lebih dari 4 jam dalam sehari yaitu 8 jam per hari. Aktivitas operator bukan hanya mengawasi billing dan user tetapi juga bermain game, menonton film atau video. Hal tersebut merupakan suatu kondisi yang dapat membuat operator saat bekerja dihadapan layar komputer atau monitor lebih lama sehingga terjadi kelelahan dan ketegangan mata yang diakibatkan karena mata yang dipaksakan untuk mengalami fokus akomodasi yang berpindah-pindah saat melihat layar komputer.

Berdasarkan hal tersebut, peneliti tertarik untuk meneliti faktor risiko keluhan Computer Vision Syndrome (CVS) terhadap Operator Warung Internet di Kecamatan Bojong Gede, Kab. Bogor Tahun 2017.

\section{Metode}

Penelitian ini dilakukan dengan menggunakan pendekatan kuntitatif dengan desain penelitian cross sectional (potomg lintang), setiap subyek penelitian hanya diobservasi sekali saja dan pengukuran dilakukan terhadap status karakter atau variabel subjek pada saat pemeriksaan. Hal ini tidak berarti bahwa semua subjek penelitian diamati pada waktu yang sama (Notoatmodjo, 2002) .

Penelitian ini dilakukan di Warung Internet (Warnet) yang berada di Kecamatan Bojong Gede, Kabupaten Bogor. Sedangkan waktu penelitian dilaksanakan pada bulan Maret sampai desember 2017 yang dimulai dari observasi awal sampai pengambilan data

Populasi dalam penelitian ini adalah semua Pekerja Operator Warnet yang berada di Desa Cimanggis, Desa Bojong Baru, Desa Waringgin Jaya, Desa Rawa Panjang, Desa Kedung Waringin, Desa Pabuaran, Desa Bojong Gede, Desa Raga Jaya dan Desa Susukan yang masuk dalam wilayah Kecamatan Bojong Gede, Kabupaten Bogor.

Sampel yang digunakan dalam penelitian ini adalah sampel jenuh dimana total pupulasi yang berjumlah 50 orang berdasarkan data primer 
peneliti yang ditemukan dilapangan semuanya dijadikan responden.

Variabel independen atau variabel bebas dari penelitian ini adalah Usia, waktu istirahat, durasi penggunaan komputer, jarak penglihatan mata ke komputer dan sudut penglihatan. Variabel dependen atau variabel terikat dalam penelitian ini adalah computer vision syndrome.

Data yang digunakan dalam penelitian ini ada 2 macam yaitu data primer dan data sekunder. Data primer dalam penelitian ini merupakan data yang diperoleh secara langsung dari sumber data yang didapatkan dengan cara pengukuran jarak penglihatan dan sudut penglihatan mata ke layar monitor, serta jumlah pekerja operator warnet yang berada di Kecamatan Bojong Gede dengan observasi langsung dilapangan.

Pengukuran jarak penglihatan mata pada layar komputer mengunakan pita meteran. Pengukuran dilakukan dari ujung mata pekerja garis lulus dengan layar komputer yang sedang digunakan. Hasil pengukuran di catat dilembar Observasi yang sudah disediakan peneliti.

Pengukuran sudut penglihatan mata pada layar komputer menggunakan Busur. Pengukuran dilakukan dengan melihat besar sudut penglihatan yang terbentuk antara sisi atas monitor dan titik tengah layar monitor saat bekerja dengan komputer untuk mengatahui sudut pengelihatan mata lebih tinggi dari tinggi layar komputer atau sejajar/lebih rendah dari titik tengah layar komputer.

\section{Hasil}

Data yang diperoleh dianalisa malalui komputer dengan menggunakan program Statistical Package for Social Science (SPSS) versi 19. Berikut hasil pengelolaan data penelitian.

Berdasarkan hasil observasi lapangan di Kecamatan Bojong Gede yang terdiri dari 9 Desa, terdapat sekitar 23 unit warung internet (warnet), yaitu: Desa Cimanggis 1 unit warnet dengan operator 3 orang, Desa Bojong Baru ada 2 unit warnet dengan operator 3 orang, Desa Waringin Jaya ada 1 unit warnet dengan 3 orang operator warnet, Desa Rawa Panjang ada 3 unit warnet dengan operator 6 orang, Desa Kedung Waringin terdapat 5 unti warnet dengan operator 10 orang, Desa Pabuaran terdapat 4 unit warnet dengan operator 10 orang, Desa Bojong Gede ada 2 unit warnet dengan operator 3 orang, Desa Ragajaya terdapat 3 unit warnet dengan operator 6 orang, Desa Susukan terdapat 2 unit Warnet dengan operator 3 orang. Sehingga total jumlah operator warung internet yang ada di Kecamatan Bojong Gede yang berada di 9 Desa sebanyak 50 orang operator.

Berdasarkan hasil analisis univariat diperoleh sebagian besar operator warung internet di Kecamatan Bojong Gede mengalami Computer Vision Syndrome (CVS) sebesar 76\% dari 50 orang dengan gejala utama yang paling banyak adalah mata Lelah dan tegang $(80 \%)$, mata sakit (76\%), penglihatan kabur/blur (58\%), sakit kepala (56\%), mata kering teriritasi (44\%), mata berair (42\%), sulit memfokuskan (42\%), penglihatan ganda (32\%).

Berdasarkan faktor individu yakni usia, ratarata berusia < 40 tahun (92\%), sedangkan yang berumur $\geq 40$ tahun hanya $8 \%$.

Berdasarkan faktor pekerjaan yaitu waktu istirahat dan durasi penggunaan komputer diperoleh bahwa operator warnet setiap <2 jam mengambil waktu istirahat sebanyak (56\%), sedangkan $\geq 2$ jam 44\%. Menurut durasi penggunaan computer $\geq 4$ jam (82\%), sedangkan $<4$ jam hanya $18 \%$.

Berdasarkan faktor Visual Display Terminal (VDT) yaitu Sudut penglihatan dan jarak ke monitor diperoleh sebagian besar operator warnet memiliki sudut penglihatan dengan posisi bagian atas monitor terhadap ketinggian horizontal mata yang lebih tinggi (lebih dari 30 derajat keatas) (60\%). sedangkan yang sejajar atau lebih rendah hanya $40 \%$. Menurut jarak 
penglihatan ke computer rata-rata berjarak $<50$ $\mathrm{m}(66 \%)$, sedangkan $>50$ hanya $34 \%$.

Dari hasil analsisis bivariat (chi square) dalam table 1 - tabel 5dapat diketahui bahwa variabel yang memiliki hubungan yang signifikan dengan keluhan Computer Vision Syndrome (CVS) adalah waktu istirahat ( $p$-value $0,016)$, durasi penggunaan komputer ( $p$-value $0,027)$, jarak penglihatan ( $p$-value 0,047$)$ dan sudut penglihatan ( $p$-value 0,035). Sedangkan variabel yang tidak berhubungan secara signifikan adalah Usia ( $p$-value 0,321 ).

Variabel durasi penggunaan komputer $>4$ jam memiliki Odd Ratio (OR) terbesar diantara variable lain yaitu 6,071 kali sehingga dapat diketahui bahwa menggunakan komputer lebih dari 4 jam memiliki risiko 6 kali lebih besar mengalami

CVS.

Tabel 1. Hubungan Usia dengan Keluhan CVS

\begin{tabular}{|c|c|c|c|c|c|c|c|c|}
\hline \multirow{3}{*}{ Usia } & \multicolumn{4}{|c|}{ Keluhan CVS } & \multirow{2}{*}{\multicolumn{2}{|c|}{ Total }} & \multirow{3}{*}{$\begin{array}{c}\text { OR } \\
(95 \% \mathrm{CI})\end{array}$} & \multirow{3}{*}{$p$-value } \\
\hline & \multicolumn{2}{|c|}{ Ada } & \multicolumn{2}{|c|}{ Tidak Ada } & & & & \\
\hline & $\mathrm{N}$ & $\%$ & $\mathrm{~N}$ & $\%$ & $\mathrm{~N}$ & $\%$ & & \\
\hline$\geq 40$ tahun & 4 & 100 & 0 & 0 & 4 & 100 & 1.353 & \\
\hline$<40$ tahun & 34 & 68 & 12 & 24 & 46 & 100 & $(1.140-1.606)$ & 0,321 \\
\hline Total & 38 & 76 & 12 & 24 & 50 & 100 & & \\
\hline
\end{tabular}

Tabel 2. Hubungan Waktu Istirahat dengan Keluhan CVS

\begin{tabular}{|c|c|c|c|c|c|c|c|c|}
\hline \multirow{3}{*}{ Waktu Istirahat } & \multicolumn{4}{|c|}{ Keluhan CVS } & \multirow{2}{*}{\multicolumn{2}{|c|}{ Total }} & \multirow{3}{*}{$\begin{array}{c}\text { OR } \\
(95 \% \mathrm{CI})\end{array}$} & \multirow{3}{*}{ p-value } \\
\hline & \multicolumn{2}{|c|}{ Ada } & \multicolumn{2}{|c|}{ Tidak Ada } & & & & \\
\hline & $\mathrm{N}$ & $\%$ & $\mathrm{~N}$ & $\%$ & $\mathrm{~N}$ & $\%$ & & \\
\hline Baik $(<2$ jam $)$ & 13 & 61,9 & 8 & 38,1 & 21 & 100 & 5,769 & \\
\hline Tidak baik ( $\geq 2$ jam $)$ & 25 & 86,2 & 4 & 13,8 & 29 & 100 & $(1,328-25,054)$ & 0,016 \\
\hline Total & 38 & 76 & 12 & 24 & 50 & 100 & & \\
\hline
\end{tabular}

Tabel 3. Hubungan Durasi Penggunaan komputer dengan Keluhan CVS

\begin{tabular}{|c|c|c|c|c|c|c|c|c|}
\hline \multirow{3}{*}{ Durasi penggunaan komputer } & \multicolumn{4}{|c|}{ Keluhan CVS } & \multirow{2}{*}{\multicolumn{2}{|c|}{ Total }} & \multirow{3}{*}{$\begin{array}{c}\text { OR } \\
(95 \% \mathrm{CI})\end{array}$} & \multirow{3}{*}{$p$-value } \\
\hline & \multicolumn{2}{|c|}{ Ada } & \multicolumn{2}{|c|}{ Tidak Ada } & & & & \\
\hline & $\mathrm{N}$ & $\%$ & $\mathrm{~N}$ & $\%$ & $\mathrm{~N}$ & $\%$ & & \\
\hline$\geq 4$ jam & 34 & 83 & 7 & 17 & 41 & 100 & 6,071 & \\
\hline$<4$ jam & 4 & 44,4 & 5 & 55,6 & 9 & 100 & $(1,294-28,494)$ & 0,027 \\
\hline Total & 38 & 76 & 12 & 24 & 50 & 100 & & \\
\hline
\end{tabular}

Tabel 4. Hubungan Sudut Penglihatan dengan Keluhan CVS

\begin{tabular}{|c|c|c|c|c|c|c|c|c|}
\hline \multirow{3}{*}{ Sudut penglihatan } & \multicolumn{4}{|c|}{ Keluhan CVS } & \multirow{2}{*}{\multicolumn{2}{|c|}{ Total }} & \multirow{3}{*}{$\begin{array}{c}\text { OR } \\
(95 \% \mathrm{CI})\end{array}$} & \multirow{3}{*}{$p$-value } \\
\hline & \multicolumn{2}{|c|}{ Ada } & \multicolumn{2}{|c|}{ Tidak Ada } & & & & \\
\hline & $\mathrm{N}$ & $\%$ & $\mathrm{~N}$ & $\%$ & $\mathrm{~N}$ & $\%$ & & \\
\hline Lebih tinggi ( $>30$ derajat keatas) & 26 & 86,7 & 4 & 13,3 & 30 & 100 & 4,333 & \\
\hline $\begin{array}{c}\text { Sejajar atau lebih rendah }(<30 \\
\text { derajat })\end{array}$ & 12 & 60 & 8 & 40 & 20 & 100 & $\begin{array}{l}(1,089- \\
17,250)\end{array}$ & 0,035 \\
\hline Total & 38 & 76 & 12 & 24 & 50 & 100 & & \\
\hline
\end{tabular}

Tabel 5. Hubungan Jarak Penglihatan dengan Keluhan CVS

\begin{tabular}{|c|c|c|c|c|c|c|c|c|}
\hline \multirow{3}{*}{ Jarak Penglihatan } & \multicolumn{4}{|c|}{ Keluhan CVS } & \multirow{2}{*}{\multicolumn{2}{|c|}{ Total }} & \multirow{3}{*}{$\begin{array}{c}\text { OR } \\
(95 \% \mathrm{CI})\end{array}$} & \multirow{3}{*}{$p$-value } \\
\hline & \multicolumn{2}{|c|}{ Ada } & \multicolumn{2}{|c|}{ Tidak Ada } & & & & \\
\hline & $\mathrm{N}$ & $\%$ & $\mathrm{~N}$ & $\%$ & $\mathrm{~N}$ & $\%$ & & \\
\hline$<50 \mathrm{~cm}$ & 28 & 84,8 & 5 & 15,2 & 33 & 100 & 3,920 & \\
\hline$\geq 50 \mathrm{~cm}$ & 10 & 58,8 & 7 & 41,2 & 17 & 100 & $(1,010-15,210)$ & 0.047 \\
\hline Total & 38 & 76 & 12 & 24 & 50 & 100 & & \\
\hline
\end{tabular}


Tabel 6. Hasil Pemodelan Terakhir Analisis Regresi Logistik Faktor Risiko Keluahan CVS

\begin{tabular}{|l|c|c|c|c|c|}
\hline \multicolumn{1}{|c|}{ Variabel } & \multirow{2}{*}{$\mathrm{B}$} & $p$-value & \multirow{2}{*}{ OR } & \multicolumn{2}{c|}{ 95\% CI } \\
\cline { 4 - 6 } & & & & Lower & Upper \\
\hline Waktu Istirahat & 2.646 & 0.012 & 14.103 & 1.81 & 109.912 \\
\hline Durasi Penggunaan Komputer & $\mathbf{3 . 3 2 8}$ & $\mathbf{0 . 0 0 5}$ & $\mathbf{2 7 . 8 8 3}$ & $\mathbf{2 . 7 7 5}$ & $\mathbf{2 8 0 . 1 7 9}$ \\
\hline Sudut Penglihatan & 1.905 & 0.084 & 6.721 & 0.777 & 58.139 \\
\hline Jarak Penglihatan & 1.837 & 0.091 & 6.28 & 0.746 & 52.888 \\
\hline
\end{tabular}

Menurut hasil analisis multivariat (regresi logistik) dalam tabel 6, diantara variabel yang signifikan berhubungan dengan keluhan CVS diperoleh kesimpulan bahwa variabel durasi penggunaan komputer merupakan faktor risiko yang paling besar atau paling dominan pengaruhnya terhadap kejadian CVS (Odd Ratio 27 kali), artinya memiliki risiko 27 kali lebih besar besar untuk mengalami Computer vision syndrome dibandingkan dengan variable yang lainnya.

\section{Pembahasan}

Berdasarkan tabel 1, diperoleh hasil bahwa rata-rata usia operator warnet $<40$ tahun dan tidak berpengaruh secara signifikan terhadap keluhan CVS. Hal ini bertentangan dengan NASD (National Aging Safety Database) dalam Maryamah (2011) yangmenyatakan bahwa usia seseorang yang semakin tua memiliki pengaruh pada kemunduran kemampuan penglihatan dalam setiap objek lingkungan sekitar. Hasil ini juga berbeda dengan studi oleh Das et al (2010) yang menyebutkan bahwa usia >40 tahun mengeluhkan ketidaknyamanan pada penglihatannya akibat penggunaan komputer dibandingkan dengan kelompok usia lain disebabkan karena berkaitan dengan proses penuaan (sehingga terjadi perubahan anatomi dan penurunan fungsi tubuh).

Berdasarkan tabel 2, menunjukkan bahwa mengambil waktu istirahat yang baik
(< 2 jam) berpengaruh secara signifikan terhadap keluhan CVS. Hasil penelitian ini juga sejalan dengan hasil penelitian Azkadina (2012) bahwa pekerja pengguna komputer yang menyempatkan istirahat selama kurang dari 10 menit berisiko menderita CVS. National Institute of Occupational Safety and Health (NIOSH) merekomendasikan istirahat 10 menit setelah 2 jam kerja VDT terus menerus untuk operator pemantauan. Seseorang yang menggunakan komputer lebih 2 jam setiap harinya mempunyai risiko besar untuk menderita CVS (AOA, 2014).

Berdasarkan 3, menunjukkan bahwa durasi penggunaan komputer $>4$ jam memiliki hubungan secara signifikan terhadap keluhan CVS. Hasil penelitian ini sesuai dengan penelitian yang dilakukan Azkadina (2012) bahwa pekerja di depan komputer selama > 4 jam secara terusmenerus mempunyai risiko 3.5 kali lipat menderita CVS dibandingkan $<4$ jam. Peningkatan jam kerja di depan komputer tanpa diselingi oleh kegiatan lain dapat menurunkan kemampuan akomodasi akibat pekerjaan mata yang selalu berulang atau terus menerus membuat mata berupaya untuk memfokuskan pandangan pada layar Visual Display Termina (VDT)l sehingga menimbulkan gejala CVS pada pekerja komputer (Blehm et al., 2005; dan Miller, 2001). 
Berdasarkan 4, menunjukkan sudut penglihatan lebih tinggi dari tinggi layar monitor (lebih dari 30 derajat keatas) secara siginifikan berhubungan dengan keluhan CVS. Hal ini seseuai dengan teori American National Standards Institute (ANSI/HFES 100-2007) bahwa posisi layar monitor berkaitan dengan postur duduk seorang penguna komputer. Pada Jarak waktu kerja yang lama dengan sudut pandang mata kekomputer pada sudut 30 derajat atau lebih dapat menyebabkan ketidaknyamanan (Chaffin, 1973).

Berdasarkan 5 menunjukkan bahwa jarak penglihatan ke monitor $<50 \mathrm{~cm}$ secara signifikan berhubungan dengan keluhan CVS. Hasil ini sejalan dengan penelitian Herry Koesyanto (2006) bahwa terdapat korelasi yang sangat signifikan antara jarak pandang dengan kelelahan mata. Studi oleh Taptagaporn et al. melaporkan bahwa jarak penglihatan yang direkomendasikan adalah 50-70 cm. Studi lain menyatakan bahwa semakin jauh monitor diletakkan (90- 100 $\mathrm{cm})$ maka dapat meminimalisasi timbulnya keluhan penglihatan.

Berdasarkan 6 diperoleh bahwa variabel durasi penggunaan komputer merupakan faktor risiko yang paling besar atau paling dominan pengaruhnya terhadap kejadian CVS (Odd Ratio 27 kali), artinya memiliki risiko 27 kali lebih besar besar untuk mengalami Computer vision syndrome dibandingkan dengan variable yang lainnya, hal ini sejalan dengan penelitian yang dilakukan Azkadina (2012) bahwa Seorang individu bekerja di depan computer lebih dari atau sama dengan empat jam secara terus-menerus dengan istirahat selama kurang dari 10 menit setelah penggunaan computer mempunyai probabilitas menderita CVS sebesar 66,8\%.

\section{Kesimpulan}

Dari penelitian ini dapat disimpulkan bahwa sebagian besar pekerja operator warnet di Bojong Gede Kabupaten Bogor mengalami keluhan CVS dengan gejala utama adalah mata lelah/tegang. Faktor risiko yang signifikan berhubugan adalah waktu istirahat $<2$ jam, durasi penggunaan computer $>4$ jam, sudut penglihatan lebih tinggi, jarak penglihatan $<50 \mathrm{~cm}$. Sedangkan faktor risiko yang paling besar pengaruhnya terhadap keluhan CVS adalah durasi penggunaan computer $>4$ jam yakni 27 kali lipat dibandingkan faktor risiko lainnya.

Disarankan kepada para operator warnet agar mengambil waktu istirahat secara berkala pada setiap 20 menit bekerja didepan computer setidaknya 20 detik dengan melihat objek atau benda yang berjaraknya sekitar 20 kaki dan sebaiknya meng-install software seperti Alarm Clock untuk mengingatkan waktu istirahat mata pada saat menggunakan computer. 


\section{Daftar Pustaka}

[1] American National Standards Institute (ANSI/HFES 100-2007). Human Factorengineering Of Computer Workstations. 2007.

[2] American Optometric Association (AOA). Computer Vision Syndrome (CVS). 2014.

[3] American Optometric Association (AOA). Computer Vision Syndrome (CVS.). http://www.aoa.org/x5374.xml Diakses 14 Juli 2017.

[4] Asosiasi Penyelenggara Jasa Internet Indonesia. Penetrasi dan Perilaku Pengguna Internet Indonesia 2016. 2016.

[5] Azkadina Amira. Hubungan antara faktor individu dan komputer terhadap kejadian Computer Vision Syndrome. Semarang: UNDIP. 2012.

[6] Blehm C, Vishnu S, Khattak A, Mitra S, Yee RW. Computer vision syndrome: a review. J Surv Ophthal. 2005.

[7] Chaffin, D.B. and Park, K.S. A lonitudinal Study of low back pain as associated with Occupational lifting factors. American Industrial Hygiene Association Journal. 1973. increasing trends for computer use. In: Proceedings of the XVth Triennial Congress of the International Ergonomics Association, Seoul, Korea. 2003

[8] Das B, Ghosh T. Assessment of Ergonomical and Occupational Health related problems among VDT Workers of West Bengal, India. Asian Journal of Medical Sciences. 2010.

[9] Gangamma et al. A clinical study on "Computer vision syndrome" and its management with Triphala eye drops and Saptamrita Lauha. Jamnagar. India. 2010.

[10] Koesyanto, Herry. Pengaruh Penerangan dan Jarak Pandang Pada Komputer terhadap Kelelahan Mata. Jurnal Kemas. 2006.

[11] Maryamah, siti. Faktor-Faktor yang Berhubungan dengan Keluhan Kelelahan mata pada pengguna Komputer di Bagian Outbond Call Gedung Graha Telkom BSD (Bumi Serpong Damai) Tanggerang Tahun 2011. Universitas Islam Negeri Syarif Hidayatullah. Jakarta. 2011.

[12] Notoatmodjo, S. Metodologi penelitian kesehatan. Jakarta. PT. Rineka Cipta. 2002

[13] Shantakumari et al. Computer use and visionrelated problems among university students in ajman, United arab emirate. Ann Med Health Sci Res. 2014.
[14] Sen et all. A study of computer-related upper limb discomfort and computer vision Syndrome. 2007.

[15] Szeto, GPY. Potential health problems faced by an Asian youth population $w$

[6] Taptagaporn S, et al. Visual comfort in VDT workstation design. J Hum Ergol Tokyo. 1995 